\title{
ECONOMICS AND THE MARKET
}

\author{
E. EFFENBERGER \\ FA. E. Roederstein, Landshut, W. Germany
}

(Received July 28, 1979)

\begin{abstract}
The world market for Thick Film and Thin Film Circuits are considered and as a result an up dated version of the
\end{abstract} figures presented at the First European Hybrid Conference for May 1977 are presented.

\section{INTRODUCTION}

It is difficult to estimate the world market of thickfilm and thinfilm circuits, because no official statistics exist neither for the common market in Europe, nor in the United States or Japan. At present available export and import statistics of various markets do not include clear definitions of the products. In future it would be very helpful if the European commission would define and standardize the concept for electronic statistics.

Further it is almost impossible to estimate the share of the captive market because most of the companies using thick or thinfilm circuits of their own production show no interest in publishing such data.

Nevertheless an attempt has been made to evaluate the world market for hybrids and resistor networks based on the achieved values gained at the European hybrid conference in Bad Homburg, May $1977^{1}$.

Table I shows the market values and the expected growth rate for the open market in USA, Japan and Europe.

Table II shows the estimated values for some of the European countries.

G. C. Waite ${ }^{2}$ reported that the captive market in USA is $75 \%$ of the total consumption, this brings the total to about $\$ 1.6$ billion for the market in the United States in 1979.

TABLE I

Open world market for thick and thinfilm circuits

\begin{tabular}{llll}
\hline & 1978 & $\begin{array}{l}\text { Expected } \\
\text { Growth rate }\end{array}$ & 1979 \\
\hline USA & $350 \mathrm{M} \mathrm{\$}$ & $18 \%$ & $415 \mathrm{M} \mathrm{\$}$ \\
JAPAN & $250 \mathrm{M} \$$ & $14 \%$ & $285 \mathrm{M} \$$ \\
EUROPE & $200 \mathrm{M} \$$ & $12 \%$ & $225 \mathrm{M} \$$ \\
\hline
\end{tabular}

TABLE II

Open market for thick and thinfilm circuits in Europe 1979:

\begin{tabular}{ll}
\hline FRANCE & $45 \mathrm{M} \$$ \\
GERMANY & $56 \mathrm{M} \$$ \\
ITALY & $23 \mathrm{M} \$$ \\
UK & $60 \mathrm{M} \$$ \\
ALL OTHERS & $41 \mathrm{M} \$$ \\
\hline
\end{tabular}

The ratio of the captive market in Germany is 50\% to $60 \%$, the military portion of that market is estimated at $20 \%$ to $25 \%$. It can be assumed that similar conditions will be found in other European countries.

\section{MARKET BY DIFFERENT SECTIONS}

Figure 1 shows the shares covered by the different open market sections of the electronic industry.

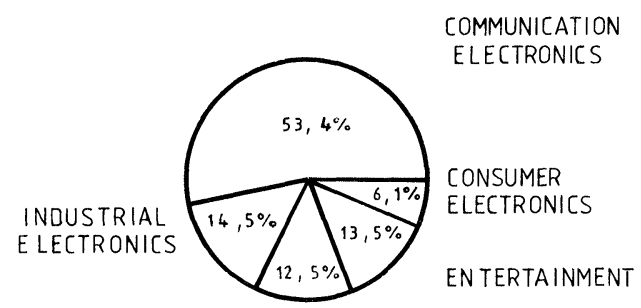

$$
\text { OFFICE ELECTRONICS }
$$$$
+ \text { COMPUTERS }
$$

FIGURE 1 Thick- and thinfilm market by different market sections.

\subsection{Entertainment}

The market requires thickfilm focus regulators, bleeders for high voltage applications, resistor 
networks for car radios and TV's. Thickfilm hybrids are used in remote control units, tuners RGBmodules, audio power packs, audio voltage amplifiers and in the color matrix.

Flip chip ICs, film carrier ICs, and also bonded ICs and transistors in plastic cases SOT 23 and SOT 89 are the preferred active components. In many cases film techniques have to compete against $\mathrm{PC}$ board techniques where partly automatic insertion machines are used.

\subsection{Consumer Electronics}

Thick film resistor networks are used in control units for washing machines. Thick film hybrid regulators have been developed as control units for vacuum cleaner motors or drilling machine motors. In movie cameras thick film hybrids with film carrier ICs are an interesting development.

\subsection{Industrial Electronics}

Generally speaking, hybrids will be replaced by monolithic ICs like microprocessors etc. Nevertheless, large fields still exist for thick film and thinfilm circuits in industrial control equipments.

\subsection{Communication Electronics}

This is the classic and largest area for thick and thinfilm circuits. Presently military application is predominant but the commercial application will also become important in future. Examples are hybrid amplifiers (thick and thinfilm) for cable TV and antenna amplifiers.

\subsection{Office Electronics}

This market is stagnating because hybrid circuits will be replaced by monolithic ICs. A great demand exists for resistor networks e.g. for pull up and pull down resistors for CMOS, TTL etc.

\subsection{Car Industry}

The car industry will become a major market and the market for electronic components will have a value of $\$ 3.8$ billion in 1985 . $\$ 1.4$ billion of this total relates to Europe. Thickfilm circuits will be used as voltage regulators for the ac-generator. Another application is the petrol injection and the ignition unit. It will not be easy to penetrate into that market because it requires a high investment by the circuit makers and high reliability and low prices for the circuits.

\section{PRICE DEVELOPMENT OF THICKFILM RESISTORS AND THICKFILM HYBRIDS}

Generally the prices of networks depend on the number of resistor elements the configuration of the elements resistor tolerances the resistor paste (TC dielectric strength) style and encapsulation.

All these parameters will influence the end-user price. For this reason it is nearly impossible to estimate an exact price per resistor element of a complex network. Nevertheless, due to the increasing demand of networks, reduced prices for ceramic substrates and pastes, improved production methods and last but not least as a consequence of the Japanese competition, the prices for thickfilm resistor networks are decreasing. We predict that this trend will continue for several years. The relative tendency is shown in Figure 2.

As far as hybrids are concerned the economics will be influenced by the hybrid design and the applied components. It can be expected that the prices for active and passive hybrid components will continue to decrease. New forms of hybridable transistors and IC packages are available and contribute to reduce the production costs. Also film carrier ICs and transistors and IC chips are the preferred components for hybrids designed for entertainment and consumer application. Fast running lasertrimming systems which also allow functional trimming, are the reason for increasing acceptance of performance. Hybrids offer economic advantages but there is also an extension of the application of this technology into areas that are using hybrids for reasons other than size and weight restrictions.

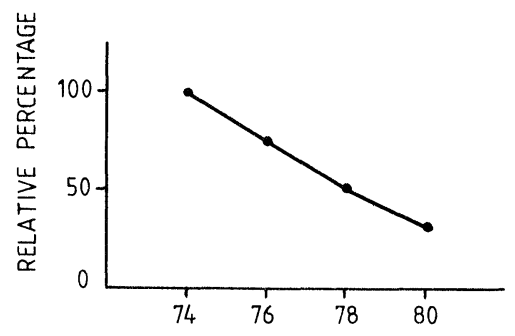

FIGURE 2 Cost per resistor element of a standard network consisting of 7 resistors.

\section{ECONOMIC INFLUENCES BY NEW FILM TECHNIQUES}

New film techniques were developed in Germany and in Japan by means of conductive plastic or polymer 
thickfilm paste. This paste is a dispersion of conductive particles of carbon in a liquidbinder on organic base. The substrate is made of plastic material. This technique has been developed as a low cost version for resistor networks and hybrids and it was announced by some companies that the prices are around $50 \%$ less compared to the existing technology. In Japan a new hybrid mounting technology was developed by Matsushita called "Hi-MIC". "The advantage is a fully automatic mounting process of chip resistors, ceramic chip capacitors, transistors in case SOT 23 and encapsulated monolithic ICs onto a PC board. Due to the automatisation of the mounting process, the hybrid can be produced very economically. The disadvantage is low complexity.
The described technologies are already in the phase of practical application as can be seen on PANASONIC's very thin radios.

In our opinion the time is now favourable for film technology and the significant growth is yet to come.

\section{REFERENCES}

1. European Hybrid Microelectronic Conf., Bad Homburg, May 1977.

2. G. C. Waite, Economic Progress of Thickfilm Hybrids in the USA. European Hybrid Microelectronic Conf., Bad Homburg, 1977.

3. S. Kamei, New Hybrid Microelectronic circuit "HI-MIC". Proc. 1978 Int. Microelec. Symp., Minneapolis. 

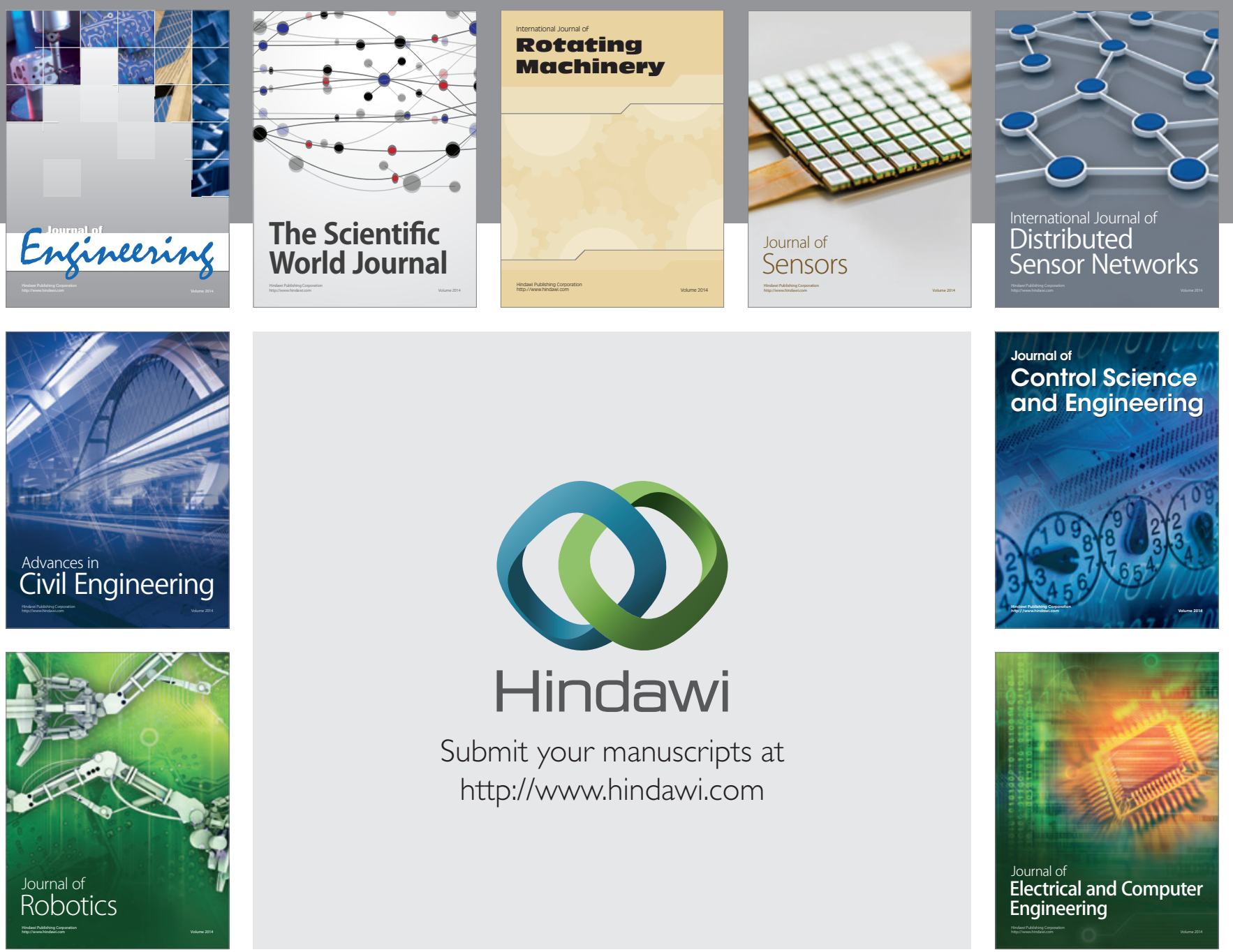

Submit your manuscripts at

http://www.hindawi.com
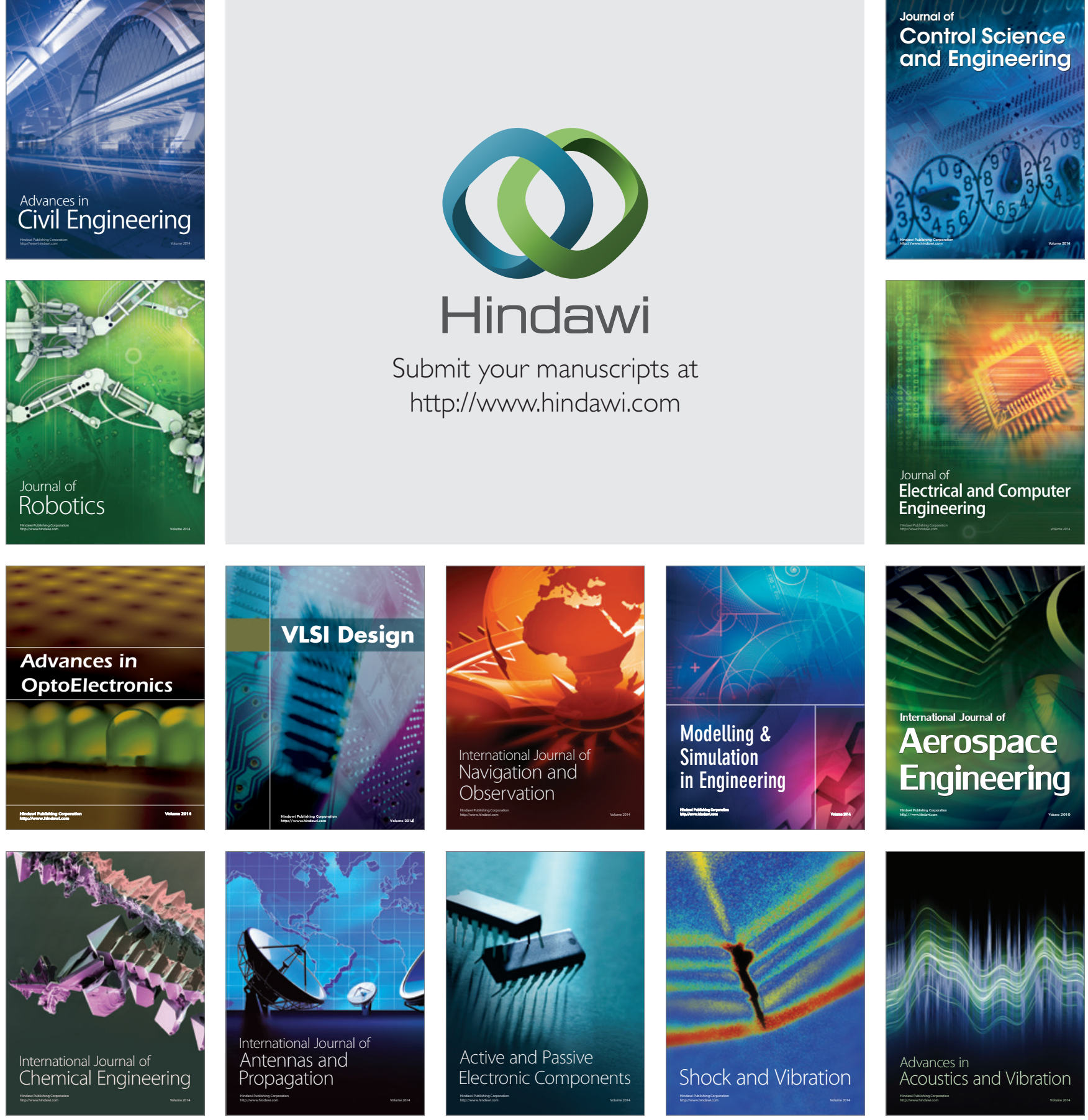